\title{
An Investigation on the Effect of Endwall Movement on the Tip Clearance Loss Using Annular Turbine Cascade
}

\author{
Hesham M. El-Batsh ${ }^{1}$ and Magdy Bassily Hanna ${ }^{2}$ \\ ${ }^{1}$ Mechanical Engineering Department, High Institute of Technology, Benha University, Benha 13512, Egypt \\ ${ }^{2}$ Mechanical Power Engineering and Energy Department, Faculty of Engineering, Minia University, Minia, Egypt
}

Correspondence should be addressed to Hesham M. El-Batsh, helbatsh@yahoo.com

Received 4 April 2011; Accepted 9 June 2011

Academic Editor: Ryo Amano

Copyright ( 2011 H. M. El-Batsh and M. Bassily Hanna. This is an open access article distributed under the Creative Commons Attribution License, which permits unrestricted use, distribution, and reproduction in any medium, provided the original work is properly cited.

\begin{abstract}
The aerodynamic losses in gas turbines are mainly caused by profile loss secondary flow, and tip leakage loss. This study focuses on tip leakage flow of high-pressure turbine stages. An annular turbine cascade was constructed with fixed blades on the casing, and the distance between blade tip and the hub was considered as tip clearance gap. The effect of endwall movement on loss mechanism was investigated by using experimental and numerical techniques. The measurements were obtained while the hub was fixed but the numerical calculations were carried out for both stationary and moving cascades. Upstream and downstream flows were measured by using a calibrated five-hole pressure probe. The steady incompressible turbulent flow was obtained by solving Reynolds averaged Navier-Stokes equations and by employing shear stress transport (SST) $k-\omega$ turbulence model. The total pressure loss coefficient obtained from the numerical technique was compared with the experimental measurements, and the comparison showed good agreement. Tip clearance vortices were observed in the tip clearance gap. It was found through this study that end-wall movement reduces tip leakage loss through the cascade.
\end{abstract}

\section{Introduction}

The applications of gas turbine engines have growing importance in the fields of electric power generation as well as marine and aerospace applications. Gas turbine engines have large powers, and, therefore, increasing the efficiency of gas turbines reduces fuel consumption and increases the economic operation of these machines. In order to increase the efficiency, detailed and fundamental comprehension of loss mechanisms is necessary. In turbines, clearance gaps are necessary to avoid the contact between rotating blades and the fixed casing. Tip leakage flow is induced due to pressure difference between blade pressure and suction surfaces. The leakage flow interacts with the passage vortex and produces aerodynamic losses. Although tip clearance in low-pressure turbines is usually about $1 \%$ of the blade height, tip clearance loss increases the total flow losses in a turbine and contributes to the efficiency degradation of gas turbines. In high-pressure stages, tip clearance gap is typically about $6 \%$ of the blade height due to the reduction of the blade length [1]. In this case, tip clearance loss has a larger influence on the overall stage loss.

In previous studies, experimental and numerical techniques were used to investigate the flow and loss mechanisms in turbine cascades. While experimental measurements give clear qualitative indications on loss levels, numerical studies provide detailed information on flow and loss mechanism in turbine blades. A number of previous experimental and numerical studies had been conducted to investigate tip leakage flow and loss mechanism using linear cascades [211]. However, linear cascades do not completely simulate the real machines where the cascades are annular and centrifugal force affects the flow. This influences pressure distribution along the blade height and the associated tip leakage flow. An annular cascade was used by Matsunuma [12] to study tip clearance flow with clearance gap of about $1 \%$ of the blade height.

Large tip clearance gaps typically $5 \%$ of the sblade height exist in the high-pressure stages of industrial gas turbines. Williams et al. [1] used experiments and computations to 

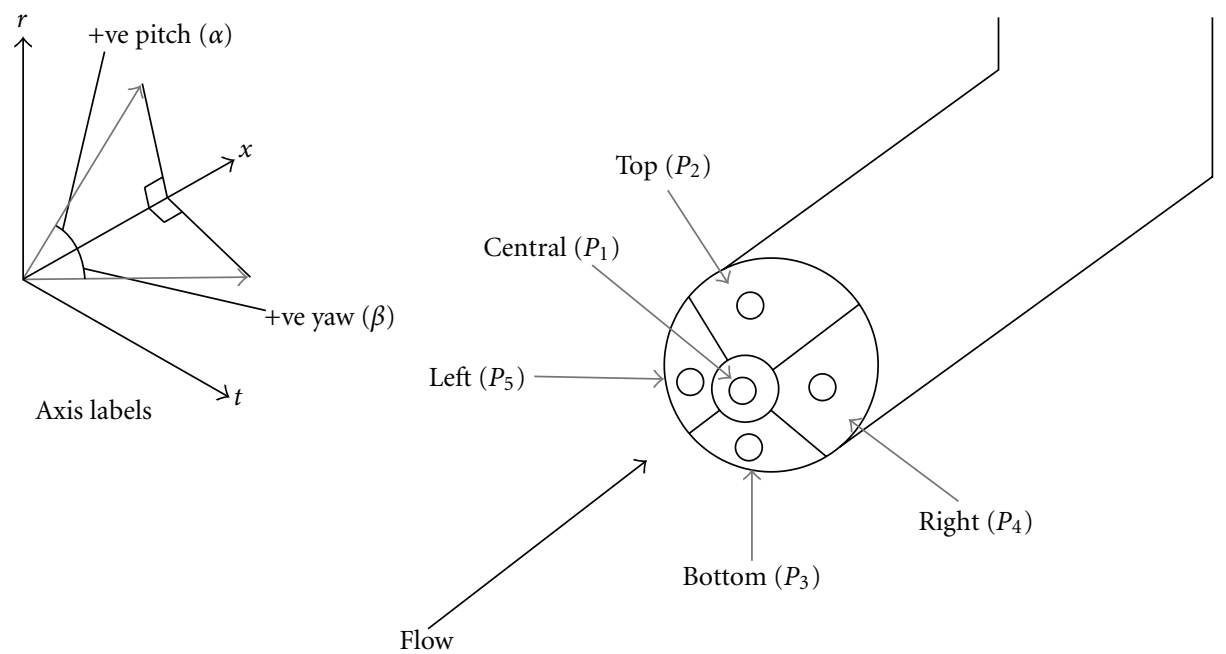

Figure 1: Five-hole probe.

investigate the effect of large tip clearance on the losses by using a linear cascade. Their results showed that the losses do not significantly increase with clearances greater than $4 \%$.

Yaras et al. [13, 14], and LaGraff and Jones [15] used a moving belt to simulate the effects of blade rotation on tip leakage flow for a linear cascade. Yang et al. [16] numerically studied the effect of rotation on the leakage flow and heat transfer of blade tip.

To the authors' knowledge, the effect of large tip clearance gaps on the losses of annular turbine cascades has not been intensively studied before. The aim of this study is to investigate the effect of large tip clearance gap on loss generation downstream of an annular turbine cascade by using experimental measurements and numerical calculations. Moreover, the study aims to investigate the effect of rotational speed on tip leakage loss. The remainder of this paper is organized by introducing detailed information on the experimental procedure including setup and measurement technique in Section 2. The numerical technique is described in Section 3. The results and discussion are given in Section 4, and finally conclusions are summarized in Section 5.

\section{Experimental Procedure}

2.1. Measurement Technique. Flow measurements were performed in the present study by using pneumatic pressure probes. The probes are reliable and robust tool for flow measurements in turbomachines. Three-hole probes are used for two-dimensional flow measurements while five-hole probes are used for the three-dimensional flow. In general, the smaller the probe used, the lower the blockage effect and the better the accuracy. Recently, many researchers used pressure probes to investigate flow losses in turbine cascades $[4,12,14,17-21]$.

Figure 1 shows the geometry of the five-hole probe used in the present study with a head diameter of $3 \mathrm{~mm}$. The measured pressures at the probe sensing holes were used to determine flow velocity. The principle of multihole pressure probes is that the holes aligned with the flow will read a higher pressure than those that are not. With a five-hole probe, the top and bottom holes will give an indication of pitch angle while the left and right holes give an indication of yaw angle as demonstrated in Figure 1.

The calibration was performed by placing the probe at a number of predefined angular settings in uniform flow with constant velocity magnitude and low turbulence intensity. After the calibration task, nondimensional calibration coefficients were obtained from the measured pressures at the probe sensing holes. A calibration map was produced by rotating the probe through a range of pitch and yaw angles. A calibration mechanism was used in this study to change pitch angle $\alpha$ and yaw angle $\beta$ of the probe. The calibration was performed for the range of yaw and pitch angles of \pm 30 . The nondimensional pressure coefficients are defined as

$$
\begin{aligned}
k_{\beta} & =\frac{\left(P_{2}-P_{3}\right)}{\left(P_{1}-\bar{P}\right)}, \\
k_{\alpha} & =\frac{\left(P_{4}-P_{5}\right)}{\left(P_{1}-\bar{P}\right)}, \\
k_{t} & =\frac{\left(P_{1}-P_{t}\right)}{\left(P_{1}-\bar{P}\right)}, \\
k_{s} & =\frac{(\bar{P}-P)}{\left(P_{1}-\bar{P}\right)}, \\
\bar{P} & =\frac{\left(P_{1}+P_{2}+P_{3}+P_{4}\right)}{4},
\end{aligned}
$$

where $P_{1}$ is the pressure measured at the central probe hole, $P_{2}, P_{3}$ are the pressures measured in the pitch plane, and $P_{4}, P_{5}$ are the pressures measured in the yaw plane. $P_{t}$ is the total pressure and $P$ is the static pressure. $k_{t}$ is the total pressure coefficient, $k_{s}$ is the static pressure coefficient, $k_{\beta}$ is the directional coefficient in pitch plane, and $k_{\alpha}$ is the 


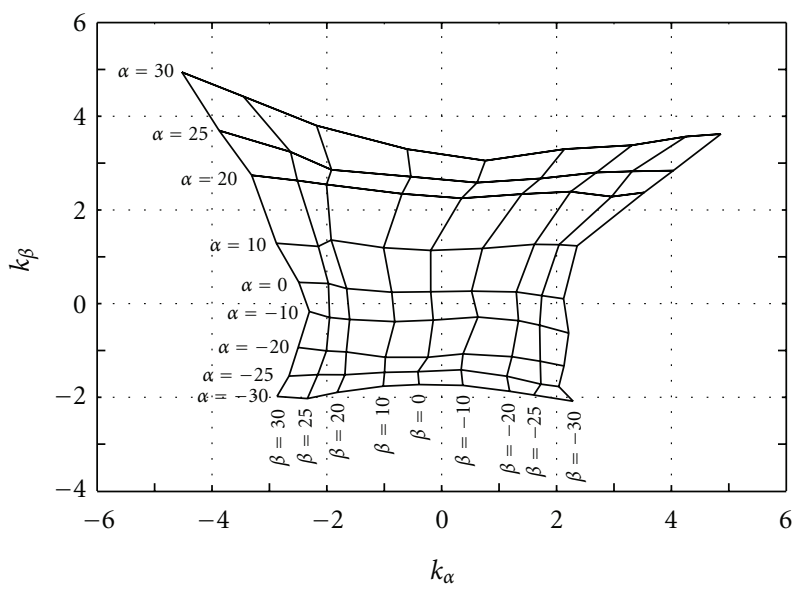

(a) $k_{\beta}$ versus $k_{\alpha}$

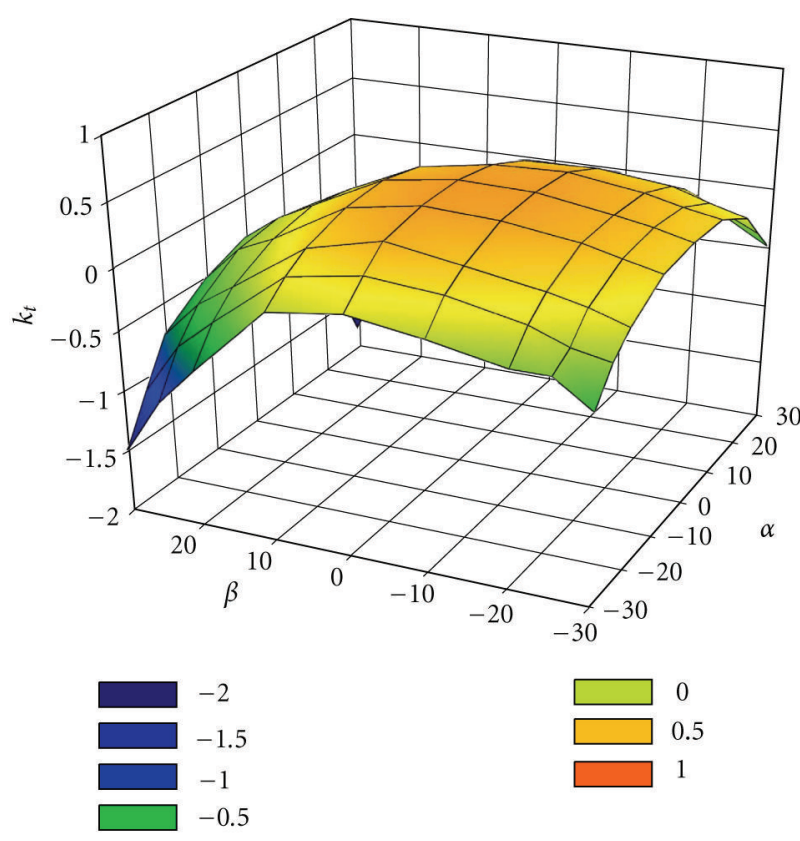

(b) $k_{t}$ versus $\alpha$ and $\beta$
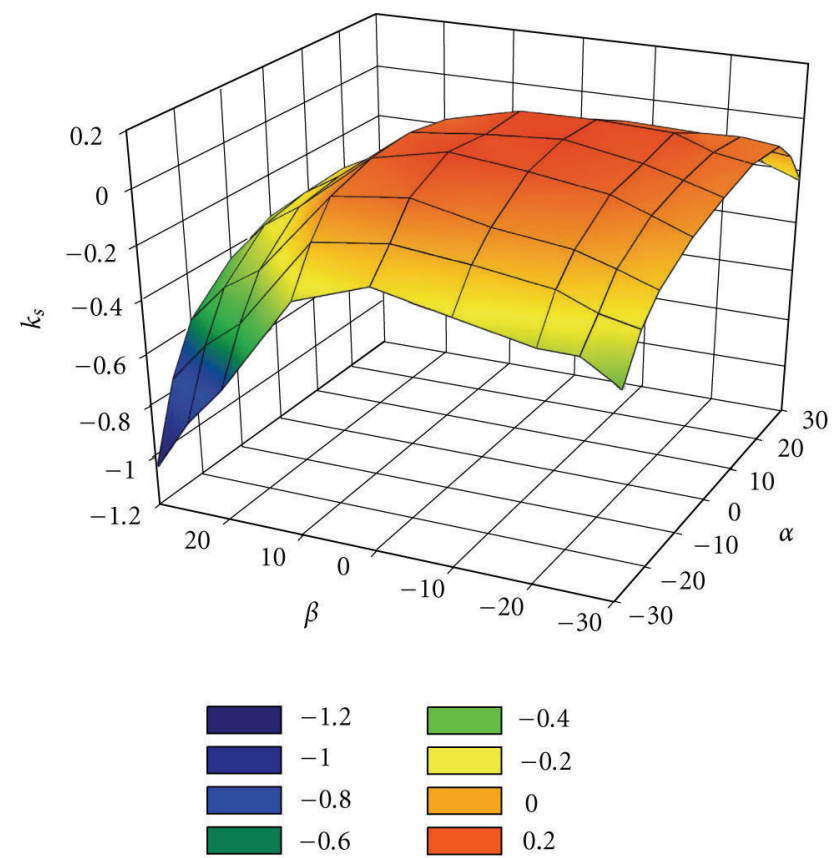

(c) $k_{s}$ versus $\alpha$ and $\beta$

Figure 2: Five-hole probe calibration maps.

directional coefficient in yaw plane. The probe is calibrated by changing the probe orientation in both directions of yaw and pitch ranging from $-30^{\circ}$ to $30^{\circ}$ with the increment of $10^{\circ}$ from $-20^{\circ}$ to $20^{\circ}$ and $5^{\circ}$ elsewhere. The pressure signals obtained from the five-hole probe were measured using five digital micromanometers with full scale of $4000 \mathrm{~Pa}$ and with error of $0.3 \%$ of the full scale. Figure 2 shows the three calibration maps which were obtained.

During cascade measurements, the pressure signals obtained from the five-hole probe were measured and the pressure coefficients were determined. The pitch angle $\alpha$ and yaw angle $\beta$ were obtained from the first calibration map using the coefficients $k_{\alpha}$ and $k_{\beta}$. Using pitch and yaw angles, the static pressure and the total pressure coefficients were obtained from the calibration maps. Then the total and static pressures were obtained as

$$
\begin{aligned}
P_{t} & =P_{1}-\left(P_{1}-\bar{P}\right) k_{t}, \\
P & =\bar{P}-\left(P_{1}-\bar{P}\right) k_{s} .
\end{aligned}
$$

Therefore,

$$
V^{2}=\frac{2}{\rho}\left(P_{t}-P\right)
$$




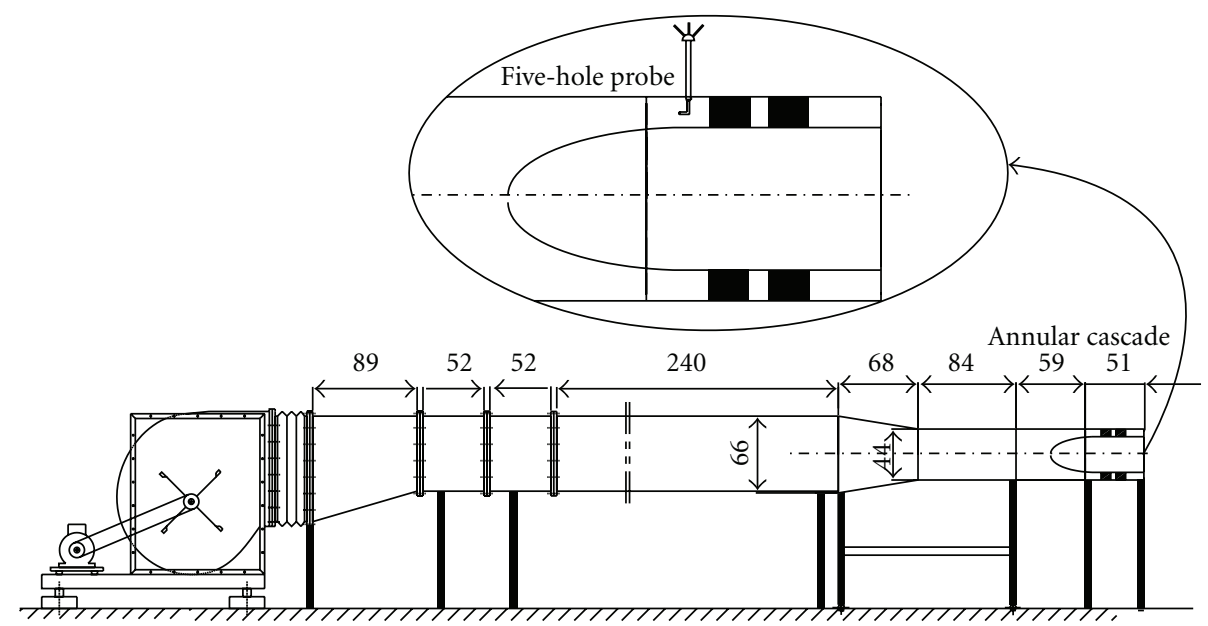

FIgURE 3: Experimental set-up.

$18^{\circ}$

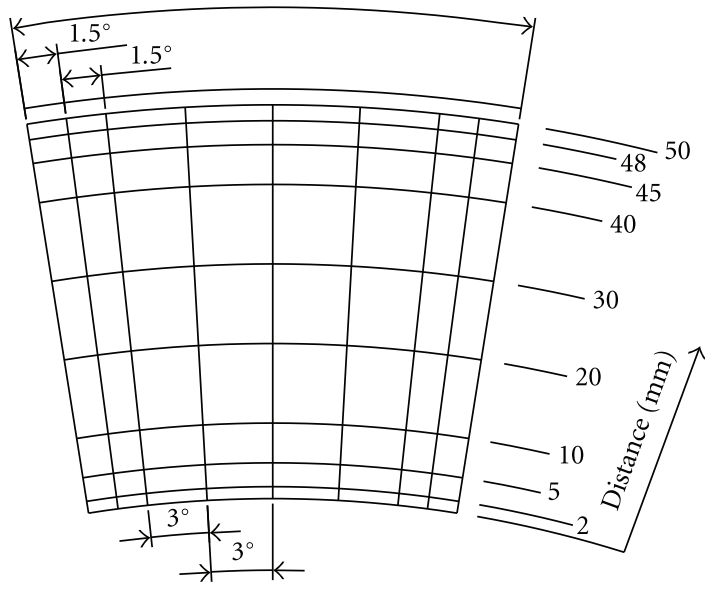

Figure 4: Measurement mesh.

Using (2), the velocity magnitude was obtained as

$$
|V|=\sqrt{\left(\frac{2}{\rho}\right)\left(P_{1}-\bar{P}\right)\left(1+k_{s}-k_{t}\right)} .
$$

The velocity components were obtained as

$$
\begin{gathered}
u=|V| \cos (\alpha) \cos (\beta), \\
v=|V| \sin (\alpha), \\
w=|V| \cos (\alpha) \sin (\beta) .
\end{gathered}
$$

2.2. Experimental Annular Cascade. A low-speed wind tunnel was used which is a blow-down facility of an annular turbine cascade (Figure 3). The wind tunnel is equipped with a centrifugal fan which is driven by a $10 \mathrm{HP}$ electric motor. Inlet air velocity is controlled by using a throttling system at fan inlet. The distance between the test section and the
TABLE 1: Specifications of the annular cascade.

\begin{tabular}{lc}
\hline Chord length, $C(\mathrm{~mm})$ & 55.2 \\
\hline Axial chord, $C_{x}(\mathrm{~mm})$ & 34 \\
Blade spacing at the tip, $S_{t}(\mathrm{~mm})$ & 46.5 \\
Blade spacing at the root, $S_{r}(\mathrm{~mm})$ & 61.9 \\
Inlet blade angle, $\beta_{1}\left(^{\circ}\right)$ & 76.1 \\
Outlet blade angle, $\beta_{2}\left(^{\circ}\right)$ & 14.5 \\
Blade turning angle, $\left(^{\circ}\right)$ & 89.4 \\
Stagger angle, $\left({ }^{\circ}\right)$ & 39.9 \\
Blade height, $h(\mathrm{~mm})$ & 44.5 \\
Tip clearance gap, $\delta(\mathrm{mm})$ & 4.5 \\
Aspect ratio, $h / C(-)$ & 0.81 \\
\hline
\end{tabular}

fan is about $4.5 \mathrm{~m}$. In order to obtain uniform flow at the inlet to the test section, three grids are used at distances of $0.89 \mathrm{~m}, 1.41 \mathrm{~m}$, and $1.93 \mathrm{~m}$. The test section of the annular cascade contains 20 high turning blades with hub diameter of $296 \mathrm{~mm}$ and casing diameter of $394 \mathrm{~mm}$. Blade spacing at the blade tip near the hub is $46.5 \mathrm{~mm}$ and $61.9 \mathrm{~mm}$ at the casing. The blades are fixed in the casing and the tip clearance gap represented the distance between the blade tip and the hub. The tip clearance represents $10 \%$ of the blade height. The hub was allowed to rotate using rotor blades which were fixed to the hub. The speed of the hub was controlled by using a break which was installed on the shaft of the hub. The measurements were obtained in this study while the hub was fixed. Table 1 lists the specifications of the annular cascade.

The velocity distribution of the inlet flow was measured upstream of the blades at a distance of an axial chord $C_{x}$. The downstream measurements were performed on a plane which exists at a distance of $0.29 C_{x}$ downstream of the blades. The measurement mesh contains 9 points in the spanwise direction and 9 points in the pitchwise direction. The measurement mesh is shown in Figure 4. 


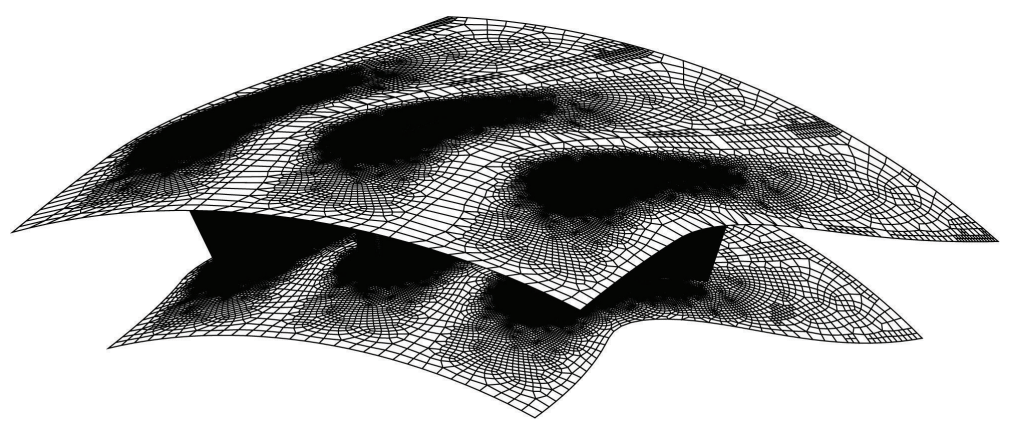

FIgURe 5: Computational grid.

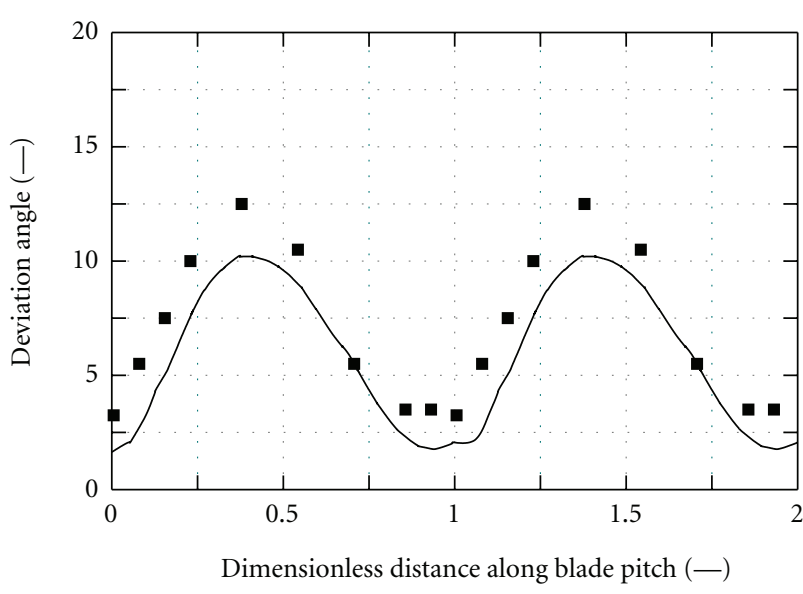

- Experimental measurements — Numerical calculations

Figure 6: Mid-span deviation angle downstream of the blade.

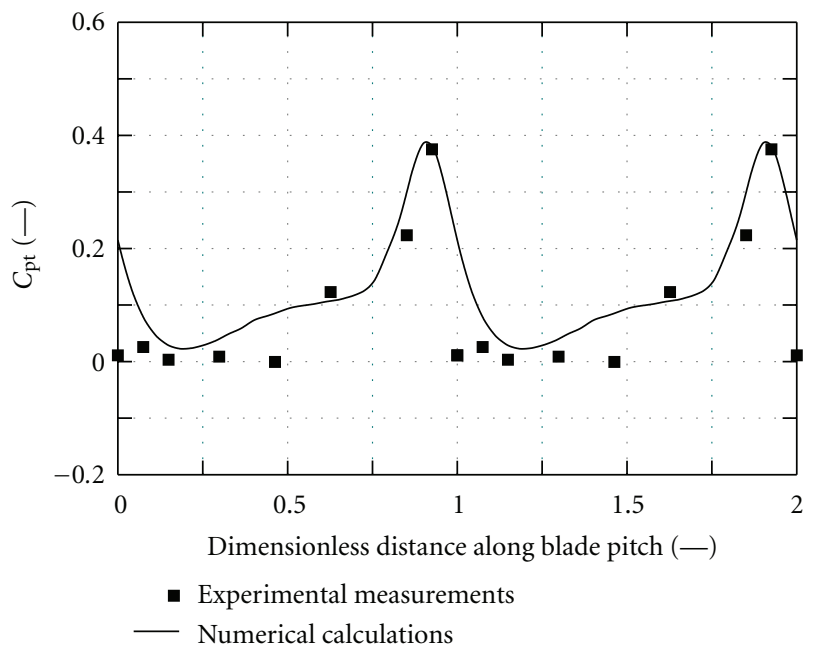

Figure 7: Mid-span wake downstream of the blade.

\section{Numerical Procedure}

The three-dimensional flow was obtained by solving continuity and momentum equations. For turbulent flow calculations, eddyviscosity approach was used. It includes a

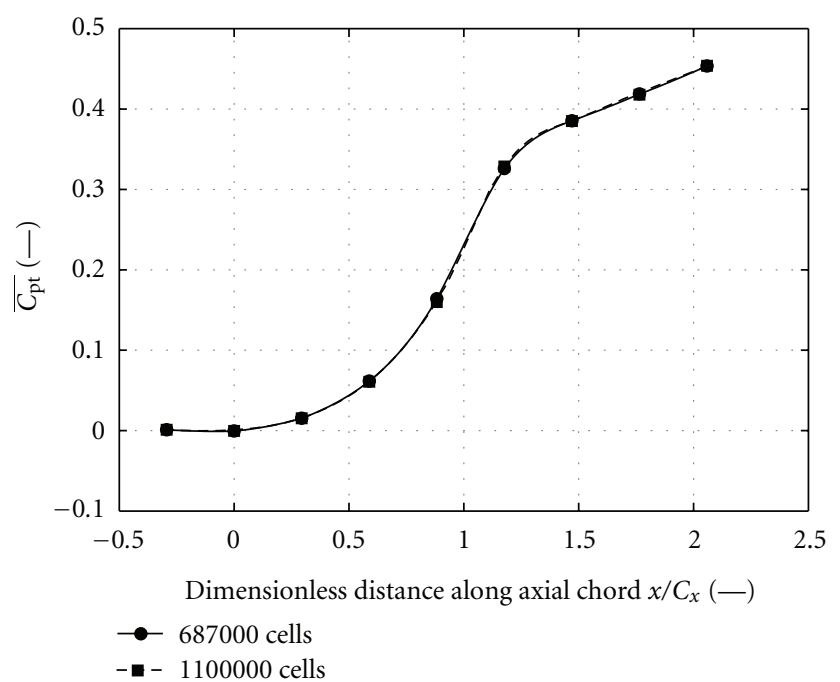

FIGURE 8: Total pressure loss coefficient through blade channel.

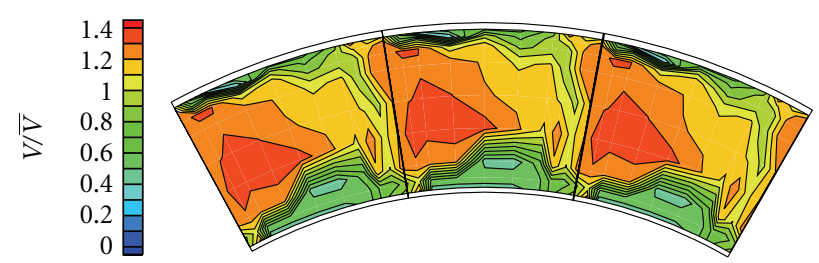

(a) Experimental measurement

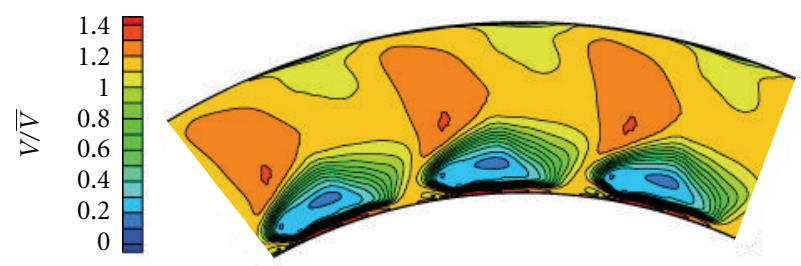

(b) Numerical calculations

FIGURE 9: Downstream dimensionless velocity.

number of classes of models which approximate the effect of the turbulence on the mean motion by modifying the coefficient of viscosity. The effective viscosity coefficient that was used in the computation of the flow field is the sum of the 


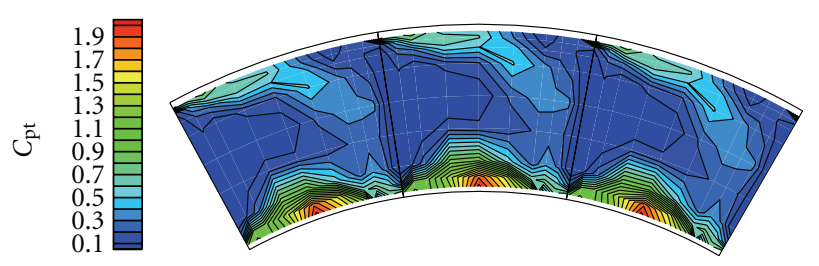

(a) Experimental measurement

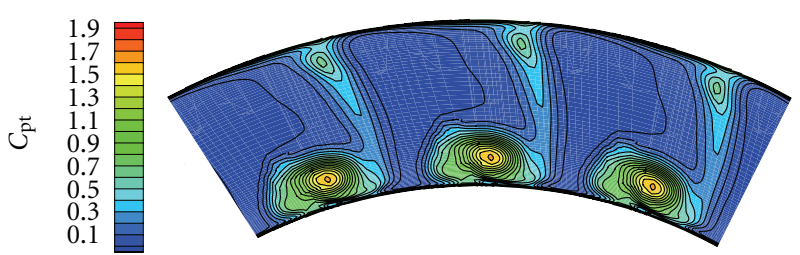

(b) Numerical calculations

Figure 10: Downstream total pressure coefficient.

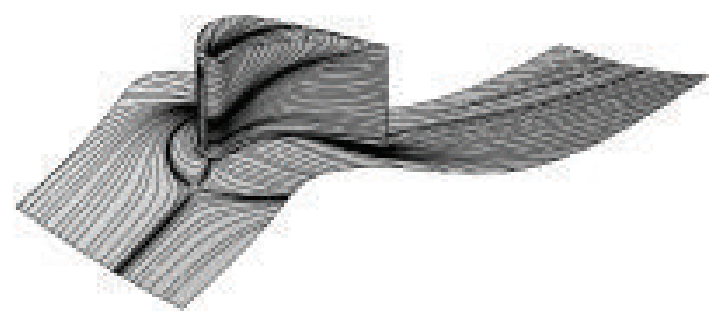

(a) Pressure side

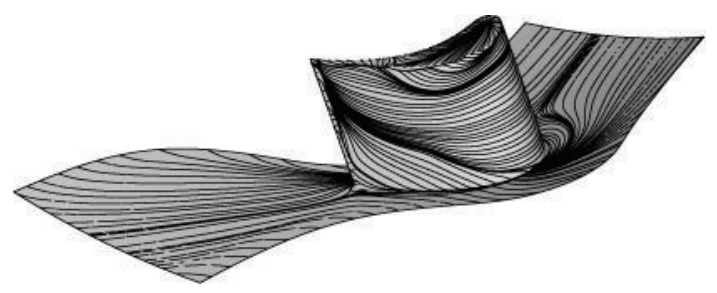

(b) Suction side

FIGURE 11: Endwall visualization.

molecular viscosity $\mu$ and the turbulent viscosity $\mu_{t}$. Different classes of eddy viscosity models are distinguished by the number of additional differential equations that are solved to determine $\mu_{t}$. Two-equation turbulence models solve two differential equations to determine the turbulence viscosity. The turbulent viscosity was calculated in this study by using the shear stress transport (SST) $k$ - $\omega$ turbulence model. This model was validated for similar flow situation in linear cascades by Krishnababu et al. [22] and El-Batsh et al. [23].

3.1. Governing Equations. The governing equations for incompressible flow are given by

$$
\begin{gathered}
\frac{\partial \bar{u}_{i}}{\partial x_{i}}=0 \\
\rho \frac{\partial}{\partial x_{j}}\left(\bar{u}_{i} \bar{u}_{j}\right)-=\frac{\partial P}{\partial x_{i}}+\frac{\partial}{\partial x_{j}}\left(\mu\left[\frac{\partial \bar{u}_{i}}{\partial x_{j}}+\frac{\partial \bar{u}_{j}}{\partial x_{i}}\right]-\rho \overline{u_{i}^{\prime} u_{j}^{\prime}}\right),
\end{gathered}
$$

where the velocities $\bar{u}_{i}$ are mean values, $u_{i}^{\prime}$ are the fluctuating ones, and $-\rho \overline{u_{i}^{\prime} u_{j}^{\prime}}$ are the Reynolds stresses which are calculated using eddy viscosity turbulence models as

$$
-\rho \overline{u_{i}^{\prime} u_{j}^{\prime}}=\mu_{t}\left(\frac{\partial \bar{u}_{i}}{\partial x_{j}}+\frac{\partial \bar{u}_{j}}{\partial x_{i}}\right)-\frac{2}{3} \rho k \delta_{i j} .
$$

The eddy or turbulent viscosity $\mu_{t}$ was calculated in this study using the shear stress transport (SST) $k-\omega$ model, $\delta_{i j}$ is the Kronecker second-order tensor given by:

$$
\delta_{i j}= \begin{cases}1 & \text { if } i=j, \\ 0 & \text { if } i \neq j .\end{cases}
$$

3.2. The SST $k$ - $\omega$ Model. The SST $k-\omega$ model is an empirical model based on model transport equations for the turbulence kinetic energy $k$ and the specific dissipation rate $\omega$. Eddy viscosity is calculated as

$$
\mu_{t}=\frac{\rho k / \omega}{\max \left(1 ;\left(\Omega F_{2}\right) /\left(a_{1} \omega\right)\right)} .
$$

In the turbulent boundary layers, the maximum value of the eddy viscosity is limited by forcing the turbulent shear stress to be bounded by the turbulent kinetic energy times constant $a_{1}$. This effect is achieved with the auxiliary function $F_{2}$ and the absolute value of vorticity $\Omega$. The auxiliary function $F_{2}$ is defined as a function of wall distance $y$ as:

$$
F_{2}=\tanh \left\{\left[\max \left(2 \frac{\sqrt{k}}{0.09 \omega y} ; \frac{500 \mu}{\rho y^{2} \omega}\right)\right]^{2}\right\} .
$$

The transport equations as developed by Menter [24] and presented by Bardina et al. [25] are

$$
\begin{gathered}
\frac{\partial}{\partial x_{j}}\left(\rho k \bar{u}_{j}-\left(\mu+\sigma_{\mathrm{k}} \mu_{t}\right) \frac{\partial k}{\partial x_{j}}\right)=\tau_{i j} S_{i j}-\beta^{*} \rho \omega k, \\
\frac{\partial}{\partial x_{j}}\left(\rho \omega \bar{u}_{j}-\left(\mu+\sigma_{\omega} \mu_{t}\right) \frac{\partial \omega}{\partial x_{j}}\right)=P_{\omega}-\beta^{\prime} \rho \omega^{2} \\
+2\left(1-F_{1}\right) \frac{\rho \sigma_{\omega 2}}{\omega} \frac{\partial k}{\partial x_{j}} \frac{\partial \omega}{\partial x_{j}} .
\end{gathered}
$$

$P_{\omega}$ is the production term of $\omega$ and is approximated as proportional to the absolute value of vorticity as

$$
P_{\omega}=\gamma^{\prime} \rho \Omega^{2}
$$

The function $F_{1}$ is designed to blend the model coefficient in the boundary layer zones. This function takes the value of one on no-slip surfaces and near one over the large portion of the boundary layer and goes to zero at the boundary layer edge. This auxiliary blending function $F_{1}$ is defined as

$$
F_{1}=\tanh \left\{\left(\min \left[\max \left[\frac{\sqrt{k}}{0.09 \omega y} ; \frac{500 \mu}{\rho y^{2} \omega}\right] ; \frac{4 \rho \sigma_{\omega 2} k}{\mathrm{CD}_{k \omega} y^{2}}\right]\right)^{4}\right\},
$$




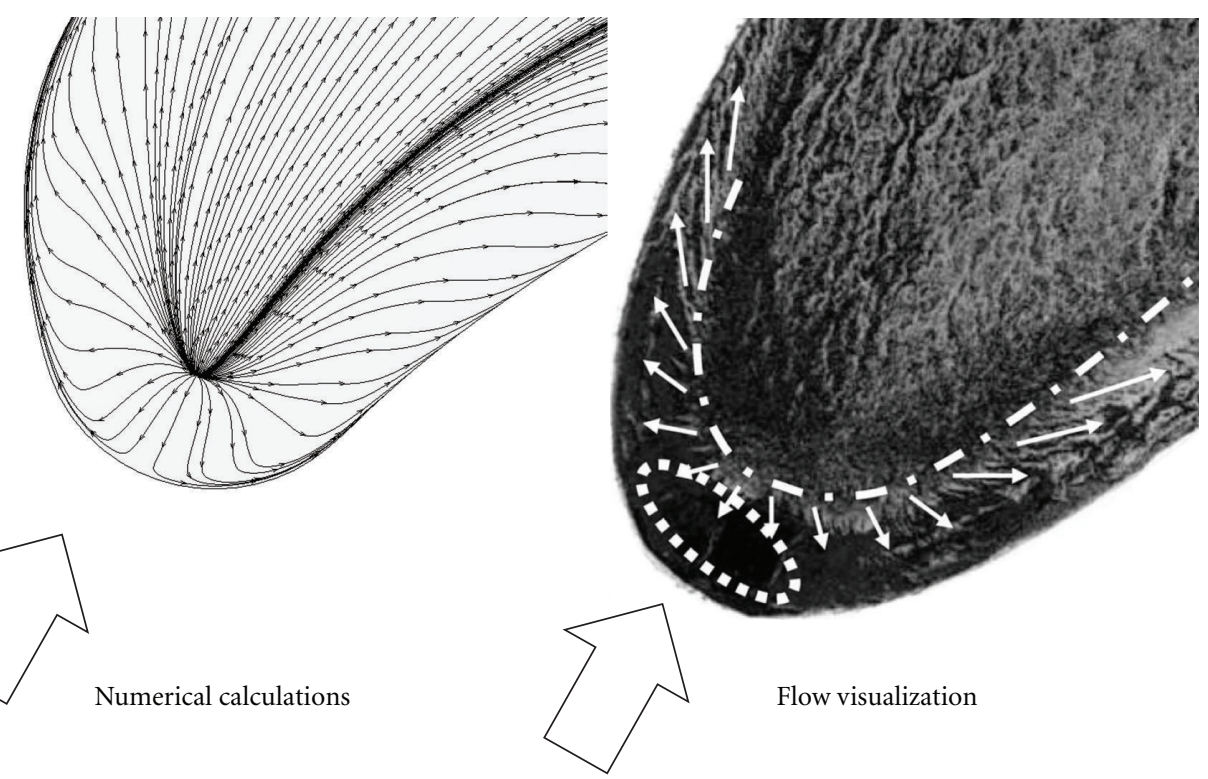

(a) Blade leading edge

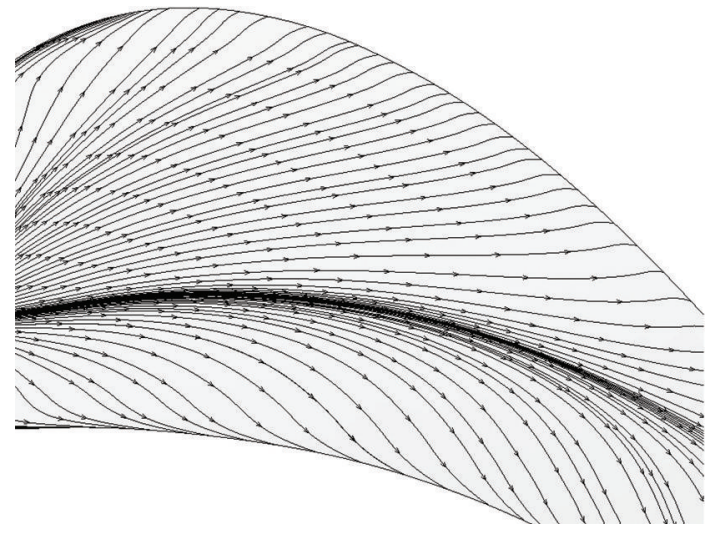

Numerical calculations

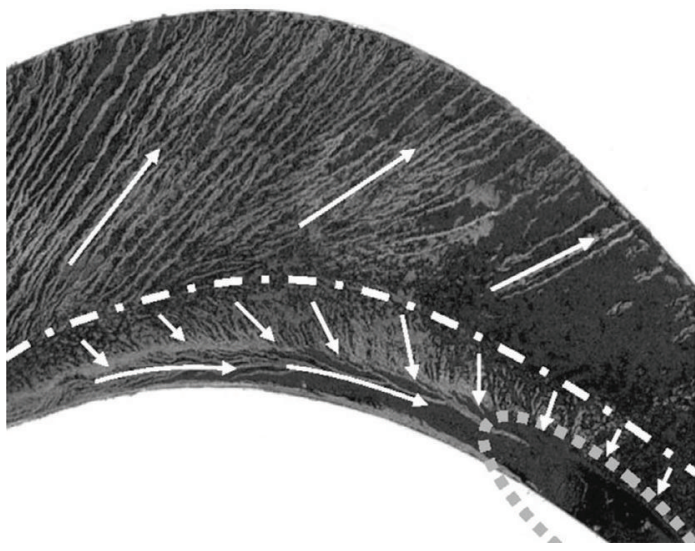

Flow visualization

(b) Blade mid-chord

FIGURE 12: Tip surface flow visualization.

where

$$
\mathrm{CD}_{k \omega}=\max \left[\frac{2 \rho \sigma_{\omega 2}}{\omega} \frac{\partial k}{\partial x_{j}} \frac{\partial \omega}{\partial x_{j}} ; 10^{-20}\right]
$$

The constants of the model are

$$
a_{1}=0.31, \quad \beta^{*}=0.09 \text {. }
$$

The model coefficients $\beta^{\prime}, \gamma^{\prime}, \sigma_{k}$, and $\sigma_{\omega}$ denoted with the symbol $\phi$ are defined by blending the coefficients of the original $k-\omega$ model, denoted by $\phi_{1}$, and the transformed coefficients denoted as $\phi_{2}$ :

$$
\phi=F_{1} \phi_{1}+\left(1-F_{1}\right) \phi_{2}
$$

where $\phi=\left\{\sigma_{k}, \sigma_{\omega}, \beta^{\prime}, \gamma^{\prime}\right\}$ and the coefficients are defined as

$$
\begin{array}{lr}
\sigma_{k 1}=0.85, & \sigma_{\omega 1}=0.5, \\
\beta_{1}^{\prime}=0.075, & \gamma_{1}^{\prime}=0.553, \\
\sigma_{k 2}=1.0, & \sigma_{\omega 2}=0.856 \\
\beta_{2}^{\prime}=0.0828, & \gamma_{2}^{\prime}=0.44 .
\end{array}
$$

3.3. Computational Grid. The flow was solved around a single blade considering periodic boundary conditions. The inlet plane was selected at a distance of $50 \mathrm{~mm}\left(1.47 C_{x}\right)$ upstream of the blade leading edge, and the outlet plane was chosen downstream of the blade trailing edge at a distance of $56 \mathrm{~mm}\left(1.65 C_{x}\right)$. The geometry was divided into three blocks to obtain the best distribution for the cells. An O-grid was used close to the blade to predict the boundary layer. Unstructured grid was used elsewhere because it provided 


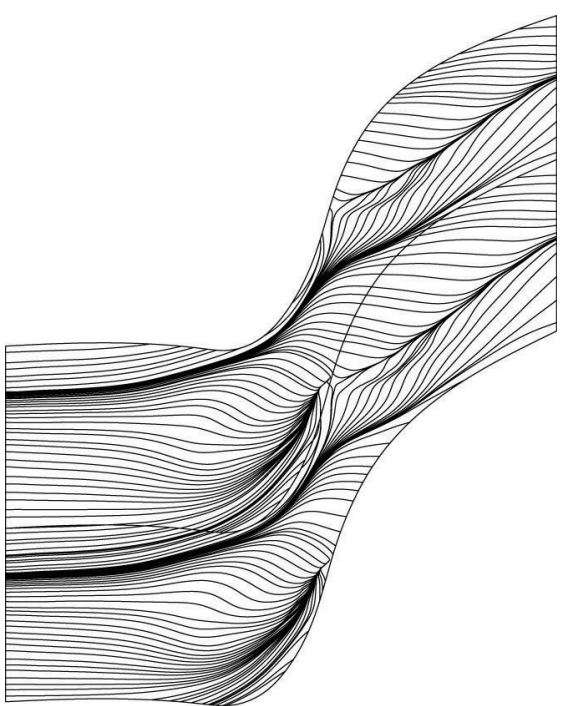

(a) Hub

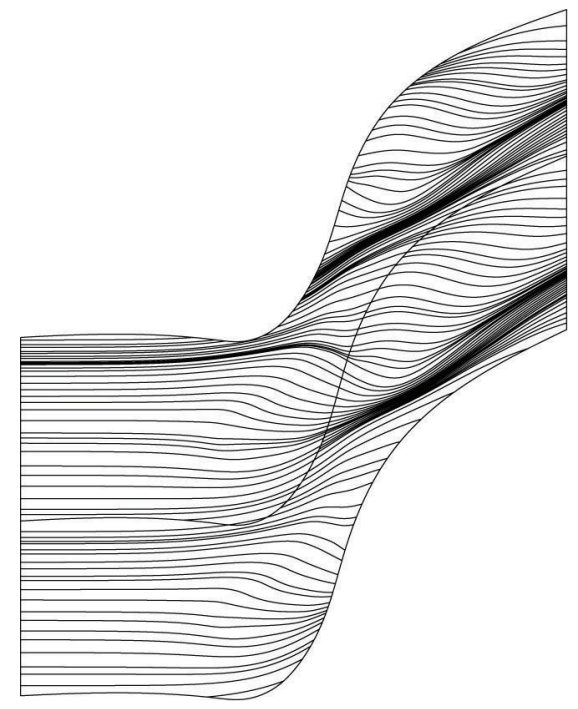

(b) Mid-clearance gap

FIgURE 13: Stream lines.

dense mesh near the walls and relatively coarse mesh far from the walls. The two-dimensional grid was generated at blade tip with 5600 cells, and then it was copied in the spanwise direction to form the three-dimensional grid. The spanwise number of cells was 80 cells along the blade height and 34 cells in the tip clearance gap. Figure 5 shows the computational grid with 687000 cells.

3.4. Boundary Conditions. The flow was solved at blade Reynolds number of $9 \times 10^{4}$ calculated based on outlet velocity and blade chord length. The velocity distribution of the incoming flow was measured in the laboratory and was applied to the calculations. Inlet turbulence parameters were estimated according to the general guidelines of CFD calculations by Casey and Wintergerste [26]. Inlet turbulence intensity was considered as $5 \%$ while inlet turbulence length

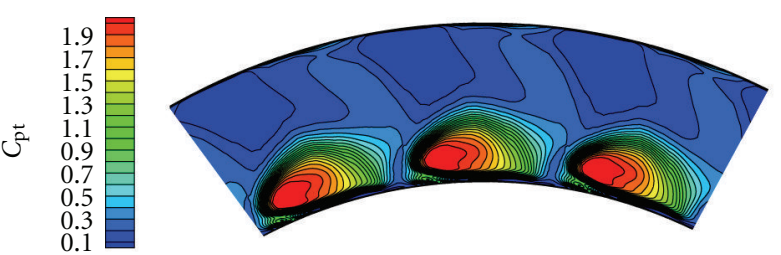

(a) Rotational speed $=800 \mathrm{rpm}$

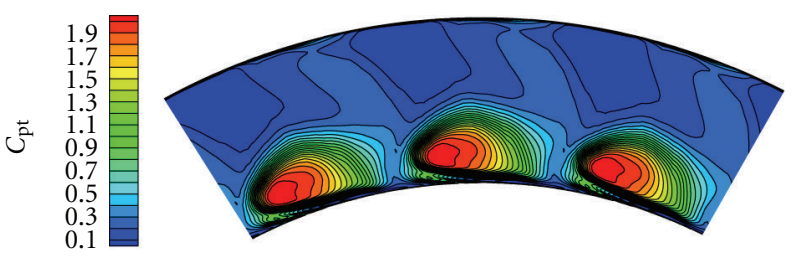

(b) Rotational speed $=1600 \mathrm{rpm}$

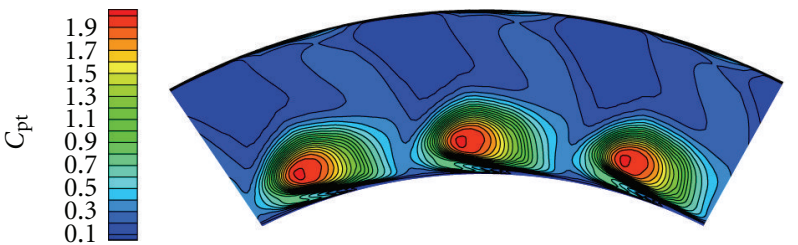

(c) Rotational speed $=3200 \mathrm{rpm}$

FIgURE 14: Total pressure coefficient at different rotational speeds.

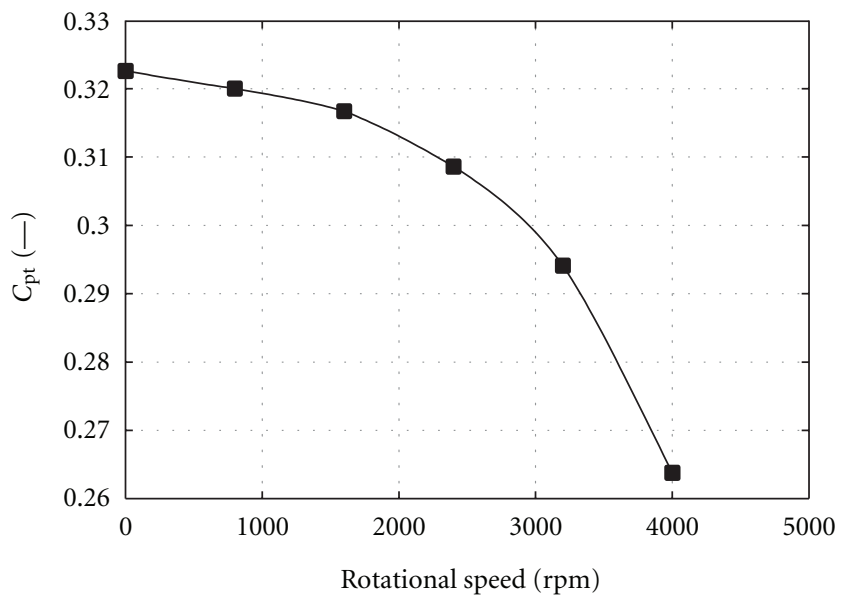

FIGURE 15: Mass-averaged total pressure loss coefficient versus rotational speed.

scale was estimated according to the dimensions of the cascade as $0.07 \mathrm{C}$. The calculations were performed for fixed and rotating hub with different rotational speeds at $800,1600,2400,3200$, and $4000 \mathrm{rpm}$. The rotational speed was estimated to represent gas turbines used in power generation and operate at 3,000 or $3,600 \mathrm{rpm}$ to match the ACpower grid.

3.5. Numerical Technique. The flow was solved by using the commercial CFD code Fluent. Pressure-velocity coupling was achieved by using SIMPLE algorithm as given by 


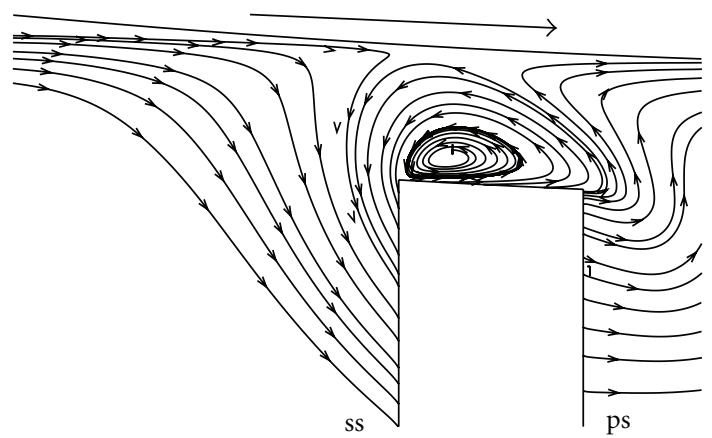

(a) with rotation

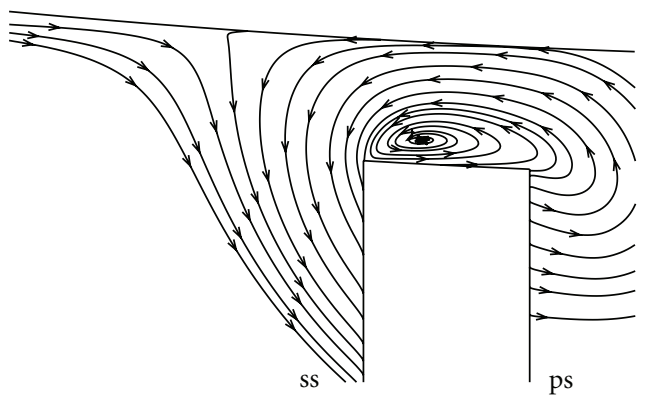

(b) without rotation

FIGURE 16: Leakage streamlines.

Patankar [27]. The equations were discretized by using second order upwind scheme.

\section{Results}

4.1. Mid-Span Flow. The three-dimensional flow downstream of the annular cascade was investigated on a plane which exists at a distance of $0.29 C_{x}$. Deviation angle represents the difference between exit flow angle and exit blade angle. Figure 6 shows the mid-span deviation angle as obtained from the experimental measurements and is compared to the numerical calculations, which shows good agreement. The deviation angle was always positive which indicates that the flow was deviated from the blade pressure surface towards the blade suction surface. This deviation was caused by the pressure difference between both blade sides.

Figure 7 shows mid-span downstream wake as demonstrated by the distribution of the total pressure coefficient $C_{\mathrm{pt}}$ which is defined as

$$
C_{\mathrm{pt}}=\frac{P_{t 1}-P_{t}}{0.5 \rho \bar{V}_{2}^{2}},
$$

where $P_{t 1}$ is the total pressure at the inlet, $P_{t}$ is the local total pressure, and $\bar{V}_{2}$ is the mass-averaged exit velocity.

The figure shows good agreement between the numerical calculations and the experimental measurements with the maximum loss near the blade trailing edge. This is attributed to the boundary layers which were developed on the blade pressure and suction surfaces and merged downstream of the blade trailing edge generating the wake.
4.2. Grid Dependency. The solution grid dependency was investigated by increasing the number of cells by $60 \%$ to obtain a mesh with a total number of cells of about 1100000 . The cells were added mainly in the boundary layer and in the regions of high flow gradients. Figure 8 shows the massaveraged total pressure loss coefficient through the blade channel as obtained by using fine and coarse grids. The massaveraged total pressure loss coefficient was defined as

$$
\overline{C_{\mathrm{pt}}}=\frac{\int \dot{m} \cdot C_{\mathrm{pt}}}{\int \dot{m}},
$$

where $\dot{m}$ and $C_{p t}$ are the local mass flow rate and total pressure coefficient, respectively.

The figure indicates that there was no significant improvement in the solution by increasing the number of the cells. The mass-averaged total pressure loss coefficient on the downstream plane was changed by $0.8 \%$ when the number of cells was increased by $60 \%$ and therefore, the solution was considered grid independent.

4.3. Downstream Flow. The velocity on the downstream plane was represented in dimensionless form using the mass averaged velocity. Figure 9 shows contour plots for the experimentally measured and the numerically calculated dimensionless velocity on the downstream plane.

Figure 10 shows contour plots for the total pressure loss coefficient as obtained from the experimental measurements and as calculated by the numerical technique. The passage vortex could be observed near the outer casing of the cascade. Good agreements were obtained between the experimental measurements and numerical calculations. At the tip clearance gap, leakage flows from the blade pressure side to the blade suction side which is driven by the pressure difference between the blade pressure and suction surfaces. The leakage flow rolls up and interacts with the passage vortex and forms a tip leakage vortex. The numerical calculations predicted that the mass-averaged total pressure loss coefficient $\overline{C_{\mathrm{pt}}}$ on the downstream plane equals 0.32 while the experimental measurements estimated $\overline{C_{\mathrm{pt}}}$ as 0.375 .

4.4. Flow Features. Figure 11 shows surface streamlines obtained from the numerical calculations using wall shear stress. Figure 11(a) shows the limiting streamlines on the casing when the blades were fixed. At the blade root, the primary separation line associated with the upstream boundary layer separation was predicted by the numerical approach. As the inlet boundary layer approaches the blade leading edge, it forms the horseshoe vortex. The horseshoe vortex is caused by rolling up of the incoming boundary layer in front of the leading edge. The migration of the endwall flow towards the suction surface is also visible resulting in the secondary flow.

Figure 11(b) shows the limiting streamlines at the suction side. A separation line is developed due to the tip leakage. This line is caused by the interaction between the leakage flow through the tip clearance and the migration of the endwall flow from the blade pressure surface to the blade suction surface. 
Figure 12 shows tip surface flow visualization using limiting streamlines and flow visualization presented by Lee et al. [19] with tip clearance of 3\% blade height. The leading edge flow features show that there exists a rolling-up of fluid separated over the tip edge and is converted into a pair of vortices which were called by Lee et al. tip gap vortices. These tip gap vortices are supported by the flow limiting streamlines in the hub given in Figure 13(a). Flow visualization at mid-chord shows that the flow is divided to the pressure surface and the suction surface and most of the flow moves toward the suction side. Figure 13(b) shows flow streamlines at mid-clearance gap which indicate that the flow migrates from the blade pressure surface to the blade suction surface.

Figure 14 shows the numerically calculated total pressure coefficient downstream of the blade trailing edge with different hub rotational speeds. The figure shows that the area covered by the high loss levels reduced by increasing the rotational speed. Figure 15 shows the mass-averaged total pressure loss coefficients $\overline{C_{\mathrm{pt}}}$ as calculated at five rotational speeds namely $800,1600,2400,3200$ and $4000 \mathrm{rpm}$. The figure indicates that increasing the rotational speed reduces the mass-averaged total pressure loss coefficient. Increasing the speed to $4000 \mathrm{rpm}$ had reduced $\overline{C_{\mathrm{pt}}}$ by about $20 \%$ of the valve calculated with fixed hub. The movement of the hub initiates counterflow from the blade suction side to the blade pressure side near the wall which reduces the tip leakage flow and the associated tip leakage vortex. This is confirmed by the streamlines obtained from the numerical calculations in the tip clearance gap in Figure 16.

\section{Conclusions}

The three-dimensional steady turbulent flow was calculated through an annular turbine cascade with tip clearance and was measured by using five-hole probe experimental technique. Good agreements were obtained between experimental measurements and numerical calculations. The numerical model predicted the rolling vortex at the blade leading edge in the tip clearance gap. Tip vortices were also predicted, which agrees with previous publications. The calculation performed at different rotational speeds showed that increasing the rotational speed reduces the tip leakage vortex and reduces also the mass-averaged total pressure loss coefficient. The rotation initiates counterflow from the blade suction side to the blade pressure side, which reduces the tip leakage flow and the associated tip leakage vortex. This observation will be confirmed experimentally in a future work.

\section{Nomenclature}

$\begin{array}{ll}a_{1}: & \text { Constant } \\ C: & \text { Chord length } \\ C_{x}: & \text { Axial chord } \\ C_{\mathrm{pt}}: & \text { Total pressure coefficient } \\ \overline{C_{\mathrm{pt}}}: & \text { Mass-averaged total pressure } \\ & \text { loss coefficient } \\ F_{1}, F_{2}: & \text { Functions }\end{array}$

\begin{tabular}{|c|c|}
\hline$h:$ & Blade height \\
\hline$k$ : & Turbulent kinetic energy \\
\hline$k_{\alpha}, k_{\beta}, k_{t}, k_{s}:$ & Probe calibration coefficients \\
\hline$P_{1}, P_{2}, P_{3}, P_{4}, P_{5}:$ & $\begin{array}{l}\text { Pressures measured at five-hole } \\
\text { probe }\end{array}$ \\
\hline$P:$ & Static pressure \\
\hline$P_{t}:$ & Total pressure \\
\hline $\bar{P}:$ & Mean pressure \\
\hline$P_{\omega}:$ & Production of $\omega$ \\
\hline$S:$ & Blade spacing \\
\hline$u^{\prime}:$ & Fluctuating velocity \\
\hline $\bar{u}:$ & Mean velocity \\
\hline $\bar{V}:$ & Mass-averaged velocity \\
\hline$x_{i}:$ & Coordinate in the $i$ th direction \\
\hline$x:$ & distance through axial chord. \\
\hline
\end{tabular}

Greek Symbols

$\begin{array}{ll}\alpha: & \text { Pitch angle } \\ \beta: & \text { Yaw angle } \\ \beta_{1}: & \text { Inlet blade angle } \\ \beta_{2}: & \text { Exit blade angle } \\ \beta^{\prime}, \gamma^{\prime}: & \text { Model coefficients } \\ \beta^{*}: & \text { Model constant } \\ \delta: & \text { Tip clearance gap } \\ \delta_{i j}: & \text { Kronecker second-order tensor } \\ \phi_{1}, \phi_{2}: & \text { Coefficients } \\ \mu: & \text { Molecular viscosity } \\ \mu_{t}: & \text { Turbulent eddy viscosity } \\ \omega: & \text { Specific turbulent dissipation rate } \\ \Omega: & \text { Absolute value of vorticity } \\ \rho: & \text { Fluid density } \\ \sigma_{k}, \sigma_{\omega}: & \text { Model coefficients. }\end{array}$

Subscripts

1: Inlet

2: Exit

t: Tip or turbulent

$r$ : Root.

\section{References}

[1] R. Williams, D. Gregory-Smith, L. He, and G. Ingram, "Experiments and computations on large tip clearance effects in a linear cascade," Journal of Turbomachinery, ASME Transactions, vol. 132, article 021018, no. 2, pp. 1-10, 2010.

[2] J. Moore and J. S. Tilton, "Tip leakage flow in a linear turbine cascade," Journal of Turbomachinery, ASME Transactions, vol. 110, no. 1, pp. 18-26, 1988.

[3] J. P. Bindon, "The measurement and formation of tip clearance loss," Journal of Turbomachinery, ASME Transactions, vol. 111, no. 3, pp. 257-263, 1989.

[4] L. Wei, Q. Weiyang, and S. Dawei, "Tip clearance flows in turbine cascades," Chinese Journal of Aeronautics, vol. 21, no. 3, pp. 193-199, 2008.

[5] X. Xiao, A. McCarter, and B. Lakshminarayana, "Tip clearance effects in a turbine rotor: part I-pressure field and loss," 
Journal of Turbomachinery, ASME Transactions, vol. 123, no. 2, pp. 296-304, 2001.

[6] X. Xiao, A. McCarter, and B. Lakshminarayana, "Tip clearance effects in a turbine rotor: part II-velocity field and flow physics," Journal of Turbomachinery, ASME Transactions, vol. 123, no. 2, pp. 305-313, 2001.

[7] J. Tallman and B. Lakshminarayana, "Numerical simulation of tip leakage flows in axial flow turbines, with emphasis on flow physics: part I-effect of tip clearance height," Journal of Turbomachinery, ASME Transactions, vol. 123, no. 2, pp. 314323, 2001.

[8] J. Tallman and B. Lakshminarayana, "Numerical simulation of tip leakage flows in axial flow turbines, with emphasis on flow physics: part II-effect of outer casing relative motion," Journal of Turbomachinery, ASME Transactions, vol. 123, no. 2, pp. 324-333, 2001.

[9] S. Krishnababu, P. Newton, B. Dawes, G. Lock, and H. Hodson, "An experimental and numerical investigation of the tip leakage flow and heat transfer using a rotor tip gap model," in Proceedings of the 6th European Turbomachinery Conference, Fluid Dynamics and Thermodynamics, Lille, France, March 2005.

[10] L. Wei, Q. Weiyang, X. Kaifu, and L. Hualing, "Numerical simulation of active control on tip leakage flow in axial turbine," Chinese Journal of Aeronautics, vol. 22, no. 2, pp. 129137, 2009.

[11] H. El-Batsh, M. Bassily Hanna, and M. F. Sherif, "An experimental and numerical study of the tip clearance effect on the three-dimensional flow field through a linear turbine cascade," in Proceedings of the 8th International Congress of Fluid Dynamics \& Propulsion, Sharm El-Shiekh, Egypt, December 2006.

[12] T. Matsunuma, "Effect of Reynolds number and free stream turbulence on tip clearance flow," ASME Paper GT 200568009, 2005.

[13] M. I. Yaras and S. A. Sjolander, "Effects of simulated rotation on tip leakage in a planar cascade of turbine blades: part I-tip gap flow," Journal of Turbomachinery, ASME Transactions, vol. 114, no. 3, pp. 652-659, 1992.

[14] M. I. Yaras, S. A. Sjolander, and R. J. Kind, "Effects of simulated rotation on tip leakage in a planar cascade of turbine blades: part II-downstream flow field and blade loading," Journal of Turbomachinery, ASME Transactions, vol. 114, no. 3, pp. 660667, 1992.

[15] J. E. LaGraff and T. V. Jones, "PIV maps of tip leakage and secondary flow fields on a low speed turbine blade cascade with moving endwall," ASME Paper GT2005-68189, 2005.

[16] D. Yang, X. Yu, and Z. Feng, "Investigation of leakage flow and heat transfer in a gas turbine blade tip with emphasismphasis on the effect of rotation," Journal of Turbomachinery, ASME Transactions, vol. 132, article 041010, no. 4, pp. 1-9, 2010.

[17] G. Ingram and D. Gregory-Smith, "An automated instrumentation system for flow and loss measurements in a cascade," Flow Measurement and Instrumentation, vol. 17, no. 1, pp. 2328, 2006.

[18] E. Sevilla, "Experimental investigation of the systematic errors of pneumatic pressure probes induced by velocity gradients, Diploma thesis," in Institute of Thermal Turbomachines and Powerplants, Vienna University of Technology, 2002.

[19] S. W. Lee, H. S. Moon, and S. E. Lee, "Tip gap height effects on flow structure and heat/mass transfer over plane tip of a highturning turbine rotor blade," International Journal of Heat and Fluid Flow, vol. 30, no. 2, pp. 198-210, 2009.
[20] B. Stephan, H. E. Gallus, and R. Niehuis, "Experimental investigation of tip clearance flow and its influence on secondary flows in a 1.5 stage axial turbine," ASME Paper, no. 2000-GT-613, 2000.

[21] R. Willinger and H. Haselbacher, "Axial turbine tip-leakage losses at off-design incidences," ASME Paper GT2004-53039, 2004.

[22] S. K. Krishnababu, H. P. Hodson, G. D. Booth, G. D. Lock, and W. N. Dawes, "Aerothermal investigation of tip leakage flow in a film cooled industrial turbine rotor," Journal of Turbomachinery, ASME Transactions, vol. 132, article 021016, no. 2, pp. 1-9, 2010.

[23] H. El-Batsh, M. Bassily Hanna, M. A. Mohamed, and M. Sherif, "Effect of the tip clearance gap on the flow and loss mechanism through a linear turbine cascade," in Proceedings of the 10th International Congress of Fluid Dynamics, Ain Soukhna, Red Sea, Egypt, December 2010, ICFD10-EG-3055.

[24] F. Menter, "Two-equation eddy-viscosity turbulence models for engineering applications," AIAA Journal, vol. 32, no. 8, pp. 1598-1605, 1994.

[25] J. E. Bardina, P. G. Huang, and T. J. Coakley, "Turbulence modeling validation, testing and development," NASA Technical Memorandum 110446, 1997.

[26] M. Casey and T. Wintergerste, "ERCOFTAC special interest group on quality and trust in industrial CFD," Best Practices Guidelines, 2000.

[27] S. Patankar, Numerical Heat Transfer and Fluid Flow, Taylor \& Francis, London, UK, 1980. 

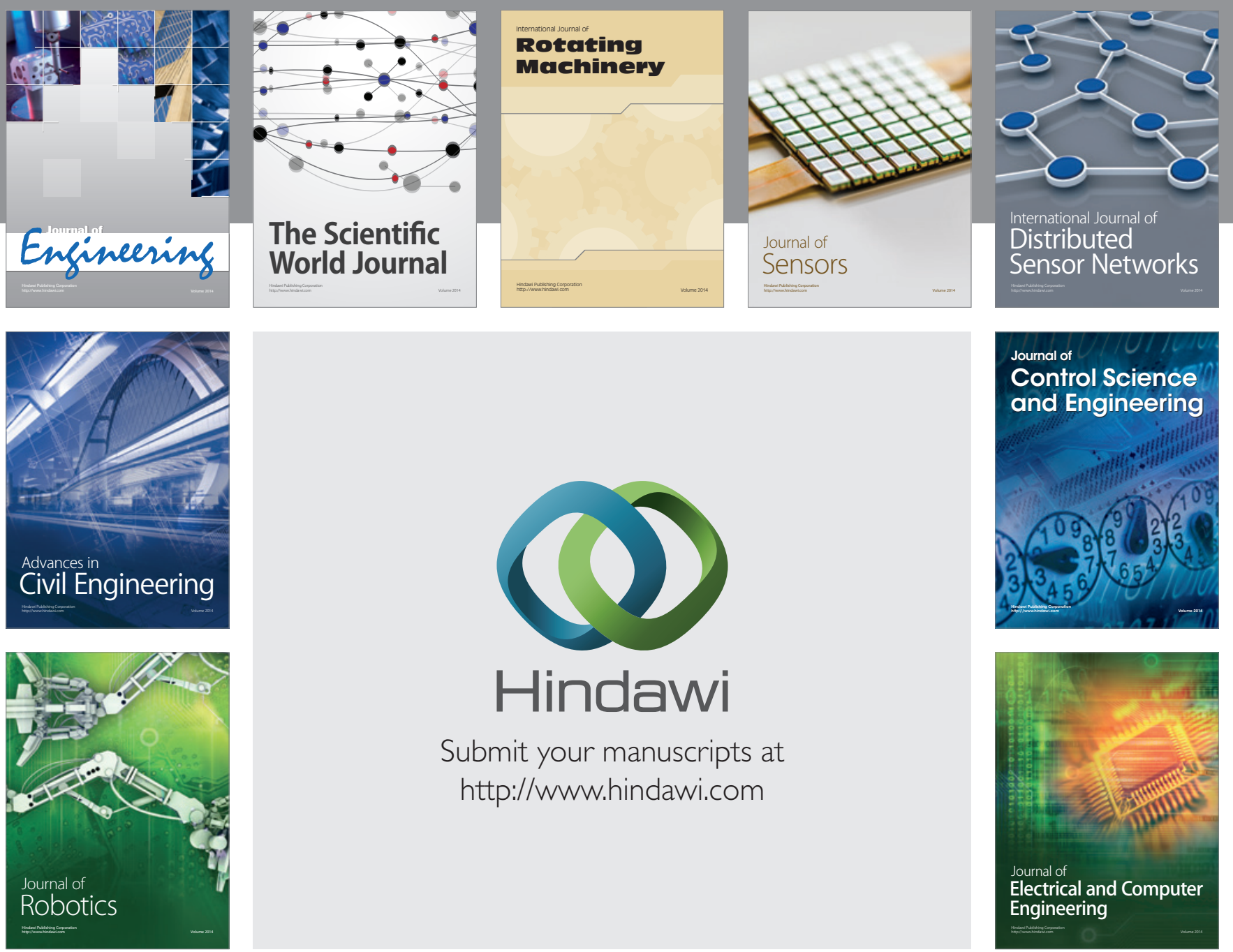

Submit your manuscripts at

http://www.hindawi.com
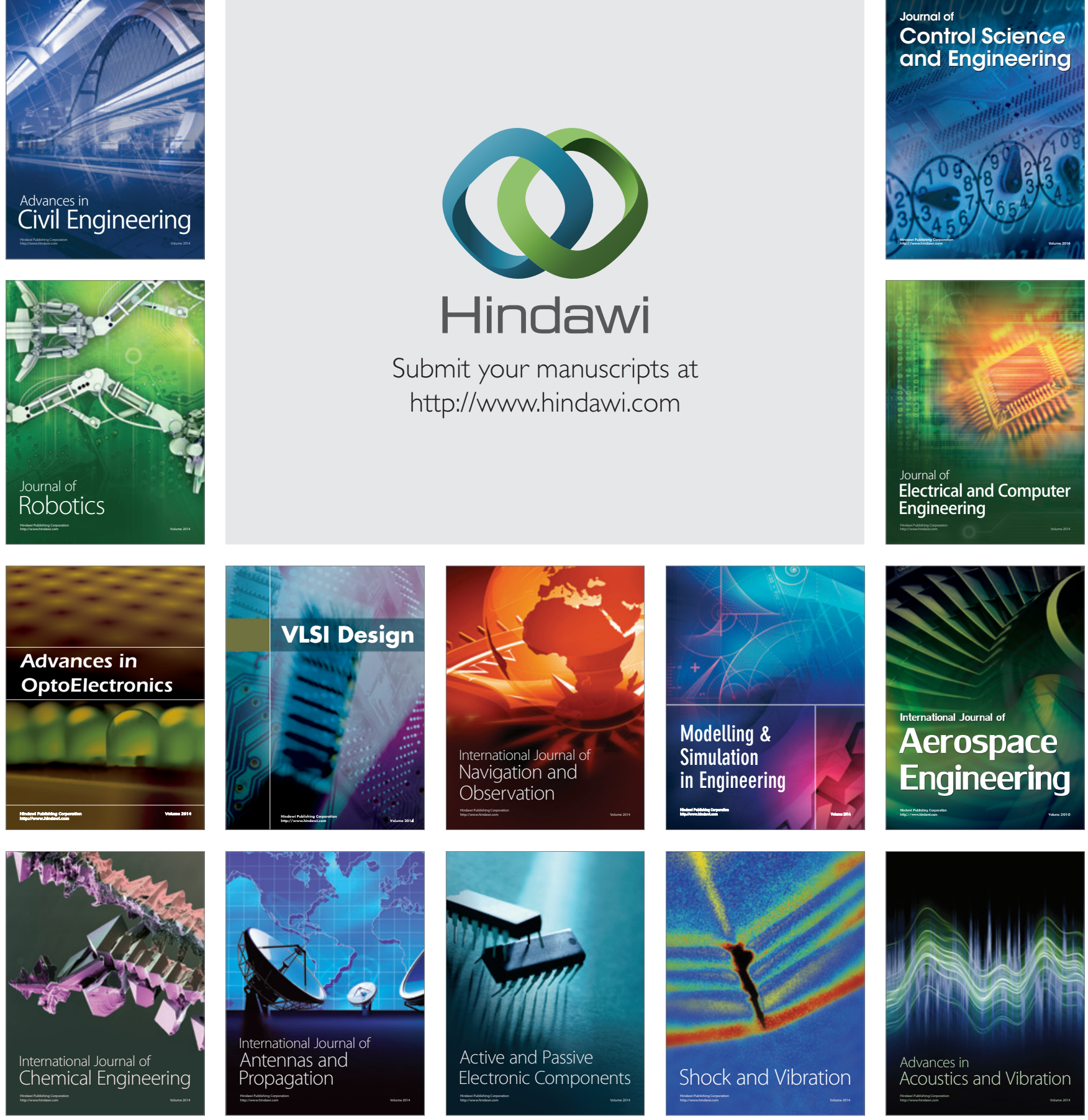